\title{
Endoscopic choledochoduodenostomy by lumen-apposing metal stent in jaundice recurrence after transpapillary metal stent placement
}

Endoscopic ultrasound-guided choledochoduodenostomy (EUS-CD) with placement of an electrocautery-enhanced lumen-apposing metal stent (EC-LAMS) has been increasingly used as an alternative treatment option in patients with distal malignant biliary obstruction and failed endoscopic retrograde cholangiopancreatography (ERCP) [1-3].

We report two cases of patients who have been referred to our unit for recurrence of obstructive jaundice after previous successful transpapillary metallic stent placement for distal malignant biliary obstruction.

Case 1 was a 90-year-old woman with previous placement of a transpapillary, partially covered, biliary, self-expandable metal stent (SEMS; $40 \times 10 \mathrm{~mm}$ ) for ampullary cancer, who presented 8 months later with recurrence of obstructive jaundice.

Deep biliary cannulation by ERCP was impossible because of neoplastic duodenal infiltration, and proximal migration of the biliary SEMS was evident at fluoroscopy. EUS-guided antegrade rendezvous was unsuccessfully attempted fol-

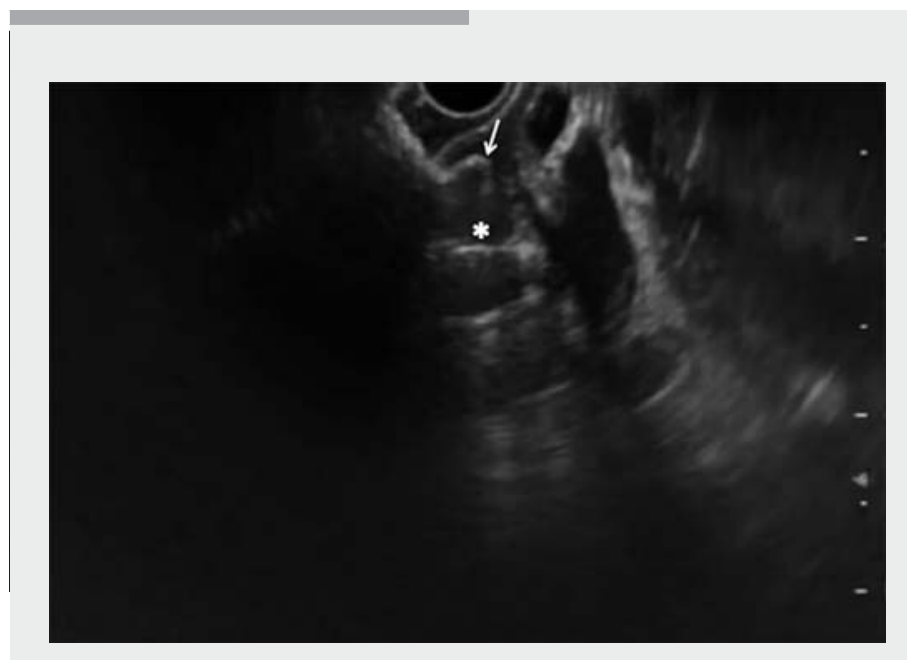

$\checkmark$ Video 1 Endoscopic ultrasound-guided choledochoduodenostomy by electrocauteryenhanced lumen-apposing metal stent and duodenal stent placement for biliary and duodenal malignant obstruction despite indwelling biliary self-expandable metal stent.

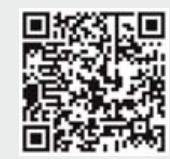

lowing failure to advance the guidewire through the biliary stenosis into the duodenum.

EUS-CD was then performed by transbulbar EC-LAMS (Hot Axios, $6 \times 8 \mathrm{~mm}$; Boston Scientific, Marlborough, Massachusetts, USA) placement despite the presence of the biliary SEMS.

Case 2 was an 81-year-old man with unresectable pancreatic cancer and previous placement of a biliary, uncovered SEMS $(60 \times 10 \mathrm{~mm})$, who presented after 9 months with gastric outlet obstruction and recurrence of obstructive jaundice. ERCP failed due to the presence of duodenal stenosis ( $\mathbf{F i g} \mathbf{1}$ ). Therefore biliary drainage by a transbulbar EC-LAMS $(6 \times 8 \mathrm{~mm})$ was performed despite the presence of the indwelling biliary SEMS

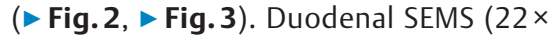
$60 \mathrm{~mm}$ Wallflex Enteral; Boston Scientific) was then placed during the same endoscopic session ( $\triangleright$ Fig. 4, \Video 1 ). No procedure-related adverse events were reported and a significant decrease in total bilirubin level was registered in both patients.

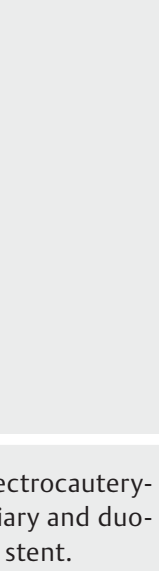

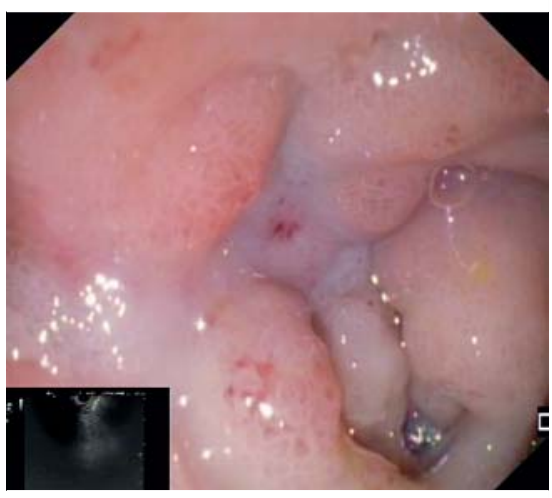

- Fig. 1 Endoscopic appearance of neoplastic duodenal infiltration.

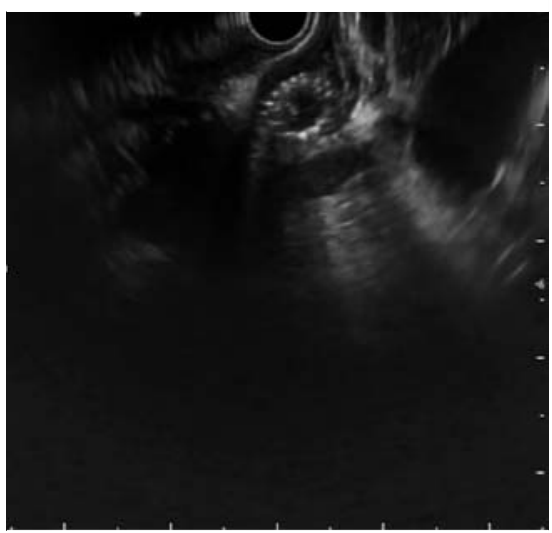

Fig. 2 Endoscopic ultrasound view of biliary self-expandable metal stent in the common bile duct.

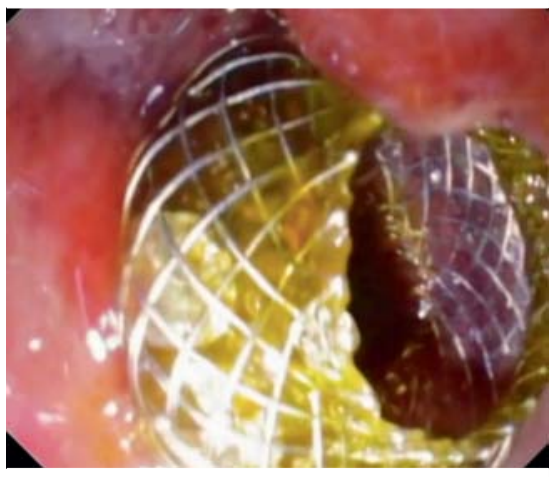

- Fig. 3 Endoscopic appearance of transduodenal lumen-apposing metal stent. 


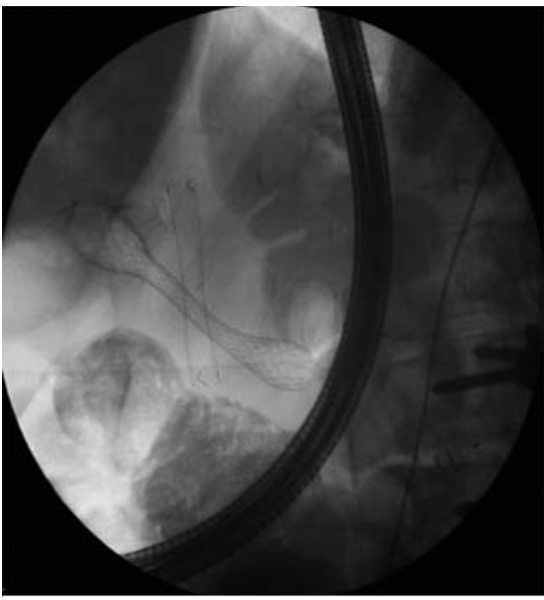

- Fig. 4 Final fluoroscopic view of biliary self-expandable metal stent, biliary lumen-apposing metal stent, and duodenal stent.

To our knowledge, these are the first cases of transduodenal LAMS placement for bile duct drainage conducted in patients with an indwelling biliary SEMS. Although the presence of a previously placed biliary SEMS could be considered a contraindication to the transluminal EUS-guided approach, the EC-LAMS system seemed to be helpful in overcoming possible technical difficulties, allowing a safe and effective procedure even in such complex conditions.

Endoscopy_UCTN_Code_TTT_1AS_2AG
Competing interests

None

The authors

Andrea Anderloni' ${ }^{1}$ Alessandro Fugazza', Gaia Pellegatta ${ }^{1}$, Edoardo Troncone ${ }^{1}$,

Simona Attardo ${ }^{1}$, Annalisa Cappello ${ }^{1}$, Alessandro Repici ${ }^{1,2}$

1 Digestive Endoscopy Unit, Division of Gastroenterology, Humanitas Research Hospital, Rozzano, Milan, Italy

2 Humanitas University, Rozzano, Milan, Italy

Corresponding author

\section{Andrea Anderloni, MD, PhD}

Digestive Endoscopy Unit, Division of Gastroenterology, Humanitas Research Hospital, Via Manzoni 56, 20089 Rozzano, Milan, Italy

$$
\text { Fax: }+39-02-82247308
$$

andrea.anderloni@humanitas.it

\section{References}

[1] Anderloni A, Buda A, Carrara S et al. Singlesession double-stent placement in concomitant malignant biliary and duodenal obstruction with a cautery-tipped lumen apposing metal stent. Endoscopy 2016; 48: E321-E322
[2] Jain D, Shah M, Patel U et al. Endoscopic ultrasound guided choledocho-enterostomy by using lumen apposing metal stent in patients with failed endoscopic retrograde cholangiopancreatography: a literature review. Digestion 2018; 98: 1 - 10

[3] Mussetto A, Fugazza A, Fuccio L et al. Through the LAMS towards the future: current uses and outcomes of lumen-apposing metal stents. Ann Gastroenterol 2018; 31: $1-6$

\section{Bibliography}

DOI https://doi.org/10.1055/a-0889-7051

Published online: 9.5.2019

Endoscopy 2019; 51: E239-E240

(c) Georg Thieme Verlag KG

Stuttgart · New York

ISSN 0013-726X

\section{ENDOSCOPY E-VIDEOS}

https://eref.thieme.de/e-videos

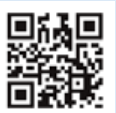

Endoscopy E-Videos is a free access online section, reporting on interesting cases and new

techniques in gastroenterological endoscopy. All papers include a high quality video and all contributions are freely accessible online.

This section has its own submission website at https://mc.manuscriptcentral.com/e-videos 